\title{
Hippocampal Histone Acetylation Regulates Object Recognition and the Estradiol-Induced Enhancement of Object Recognition
}

\author{
Zaorui Zhao, ${ }^{1,2}$ Lu Fan, ${ }^{1,3,4}$ Ashley M. Fortress, ${ }^{5}$ Marissa I. Boulware, ${ }^{5}$ and Karyn M. Frick ${ }^{1,5}$ \\ ${ }^{1}$ Department of Psychology, Yale University, New Haven, Connecticut 06520, ${ }^{2}$ Department of Anesthesiology and the Center for Shock, Trauma and \\ Anesthesiology Research (STAR), University of Maryland School of Medicine, Baltimore, Maryland 21201, ${ }^{3}$ Department of Pharmacology, Yale University \\ School of Medicine, New Haven, Connecticut 06520, ${ }^{4}$ Department of Neurology, Changhai Hospital, Shanghai 200433, People's Republic of China, and \\ ${ }^{5}$ Department of Psychology, University of Wisconsin-Milwaukee, Milwaukee, Wisconsin 53211
}

Histone acetylation has recently been implicated in learning and memory processes, yet necessity of histone acetylation for such processes has not been demonstrated using pharmacological inhibitors of histone acetyltransferases (HATs). As such, the present study tested whether garcinol, a potent HAT inhibitor in vitro, could impair hippocampal memory consolidation and block the memoryenhancing effects of the modulatory hormone $17 \beta$-estradiol $\left(\mathrm{E}_{2}\right)$. We first showed that bilateral infusion of garcinol $(0.1,1$, or $10 \mu \mathrm{g} / \mathrm{side})$ into the dorsal hippocampus (DH) immediately after training impaired object recognition memory consolidation in ovariectomized female mice. A behaviorally effective dose of garcinol $(10 \mu \mathrm{g} /$ side $)$ also significantly decreased DH HAT activity. We next examined whether DH infusion of a behaviorally subeffective dose of garcinol ( $1 \mathrm{ng} /$ side) could block the effects of $\mathrm{DH} \mathrm{E}_{2}$ infusion on object recognition and epigenetic processes. Immediately after training, ovariectomized female mice received bilateral DH infusions of vehicle, $\mathrm{E}_{2}(5 \mu \mathrm{g} / \mathrm{side})$, garcinol (1 ng/side), or $\mathrm{E}_{2}$ plus garcinol. Forty-eight hours later, garcinol blocked the memory-enhancing effects of $\mathrm{E}_{2}$. Garcinol also reversed the $\mathrm{E}_{2}$-induced increase in DH histone $\mathrm{H} 3$ acetylation, $\mathrm{HAT}$ activity, and levels of the de novo methyltransferase DNMT3B, as well as the $\mathrm{E}_{2}$-induced decrease in levels of the memory repressor protein histone deacetylase 2. Collectively, these findings suggest that histone acetylation is critical for object recognition memory consolidation and the beneficial effects of $\mathrm{E}_{2}$ on object recognition. Importantly, this work demonstrates that the role of histone acetylation in memory processes can be studied using a HAT inhibitor.

\section{Introduction}

Epigenetic processes, such as histone acetylation and DNA methylation, are critical regulators of long-term hippocampal memory formation (Levenson et al., 2004; Miller and Sweatt, 2007). The role of histone acetylation in memory has been intensively explored in recent years. The basic element of chromatin is the nucleosome, comprised of a histone octamer containing two molecules of each of the four core histones (H2A, H2B, H3 and $\mathrm{H} 4$ ), around which is wrapped superhelical DNA (Luger et al., 1997). Amino acid residues on histone tails can be modified in numerous ways, including acetylation, which relaxes the bond between histones and DNA, allowing access to transcriptional factors (Strahl and Allis, 2000). Histone acetylation is controlled by a dynamic balance between histone acetyltransferases (HATs) and histone deacetylases (HDACs) (Yang and Seto, 2007). HDAC

Received Nov. 21, 2011; accepted Jan. 3, 2012.

Author contributions: Z.Z., L.F., M.I.B., and K.M.F. designed research; Z.Z., L.F., A.M.F., and M.I.B. performed research; Z.Z. and A.M.F. analyzed data; Z.Z. and K.M.F. wrote the paper.

This project was supported by a grant from the National Institute on Aging (AG022525) to K.M.F., Yale University, and the University of Wisconsin-Milwaukee.

Correspondence should be addressed to Dr. Karyn M. Frick, Department of Psychology, University of WisconsinMilwaukee, 2441 E. Hartford Avenue, Milwaukee, WI 53211. E-mail: frickk@uwm.edu.

DOI:10.1523/JNEUROSCI.5819-11.2012

Copyright $\odot 2012$ the authors $\quad 0270-6474 / 12 / 322344-08 \$ 15.00 / 0$ inhibitors increase histone $\mathrm{H} 3$ and $\mathrm{H} 4$ acetylation in the dorsal hippocampus $(\mathrm{DH})$, enhance several types of hippocampaldependent memories, including contextual fear, object recognition and spatial memory in rodents (Stefanko et al., 2009; Zhao et al., 2010; Haettig et al., 2011), and rescue hippocampal memory deficits in mouse models of Alzheimer's disease (Ricobaraza et al., 2009; Kilgore et al., 2010).

To date, no studies have examined the effects of HAT inhibitors on memory because few viable inhibitors have been isolated or synthesized. Of the HATs studied, p300/CBP and PCAF (p300/ CBP-associated factor) are most often implicated in hippocampal learning and memory. Mice with mutations of p300 (Oliveira et al., 2007), CBP (Alarcón et al., 2004; Korzus et al., 2004; Wood et al., 2005), or PCAF (Maurice et al., 2008; Duclot et al., 2010) exhibit impaired hippocampal memory and long-term potentiation. However, inhibiting HAT activity with drugs has proven challenging, as most inhibitors of p300/CBP and PCAF generated to date cannot be used in vivo due to their cell impermeability and metabolic instability (Dal Piaz et al., 2010). Recent in vitro studies have identified garcinol, a polyisoprenylated benzophenone isolated from the Garcinia indica fruit rind, as the first nonspecific HAT inhibitor that is highly permeable to cultured cells (Balasubramanyam et al., 2004; Mantelingu et al., 2007). 
Garcinol is a potent inhibitor of both p300 and PCAF, inhibits p300 transcriptional activity, induces apoptosis, and alters gene expression (Balasubramanyam et al., 2004). Garcinol also inhibits activation of ERK and PI3K/Akt in colorectal cell lines (Liao et al., 2005b) and enhances neural survival of cortical astrocytes (Weng et al., 2011). Further, garcinol exhibits anti-oxidant, anti-inflammatory, anti-proliferative, and antiviral abilities, and so has been explored as a treatment for conditions including cancer, AIDS, ulcers, and allergies (Liao et al., 2005a; Padhye et al., 2009). However, the effects of garcinol in vivo on brain function or behavior have yet to be studied.

The present study determined whether garcinol prevents object recognition memory consolidation both alone, and in the presence of the sex steroid hormone $17 \beta$-estradiol $\left(\mathrm{E}_{2}\right)$. We recently demonstrated that activation of the extracellular signalregulated/mitogen activated kinase (ERK/MAPK) cell signaling cascade in the $\mathrm{DH}$ is necessary for $\mathrm{E}_{2}$ to enhance object recognition memory consolidation in young and middle-aged female mice (Fernandez et al., 2008; Fan et al., 2010). Further, we showed that ERK-driven epigenetic alterations, such as histone acetylation and DNA methylation, also play important roles in the memory-enhancing effects of $\mathrm{E}_{2}$ (Zhao et al., 2010). ERK activation leads to gene transcription, primarily through the transcription factor cAMP response element-binding protein (CREB), which interacts with HATs to promote transcription (Selvi et al., 2010). Infusion of $E_{2}$ into the $D H$ increased acetylation of histone $\mathrm{H} 3$, but not histone $\mathrm{H} 4$, an effect dependent on DH ERK activation (Zhao et al., 2010). $\mathrm{E}_{2}$ also decreased DH expression of histone deacetylase 2 (HDAC2) (Zhao et al., 2010), an enzyme which negatively modulates hippocampal memory and plasticity (Guan et al., 2009). Although our previous work suggested a critical role of histone acetylation in the mnemonic effects of $E_{2}$, it did not demonstrate that this acetylation was necessary for $\mathrm{E}_{2}$ to enhance memory. The present study examined this issue by determining whether garcinol could block the effects of $E_{2}$ on object recognition and hippocampal epigenetic processes. This first in vivo investigation of the mnemonic effects of a HAT inhibitor sheds light on a novel pharmacological tool for understanding the role of histone acetylation on memory processes.

\section{Materials and Methods}

Subjects. Female C57BL/6 mice were obtained from Taconic at 12 weeks of age and housed individually in shoebox cages in a room $\left(22-23^{\circ} \mathrm{C}\right)$ with a $12 \mathrm{~h}$ light/dark cycle. Food and water were provided ad libitum. Mice were handled briefly before use. Procedures were conducted from 10:00 A.M. to 5:00 P.M. in a quiet room, and experimenters conducting behavioral testing were blind to the treatment each mouse received. All procedures were approved by the Animal Care and Use Committees of Yale University and the University of Wisconsin-Milwaukee, and are consistent with the National Institutes of Health Guidelines for the Care and Use of Laboratory Animals.

Surgery. Mice were bilaterally ovariectomized and implanted with guide cannulae during the same surgical session as described previously (Fernandez et al., 2008). Mice were anesthetized using isoflurane gas (5\% for induction, $2 \%$ for maintenance) in $100 \%$ oxygen and placed in a stereotaxic apparatus (Kopf Instruments). Immediately after ovariectomy, mice were implanted with stainless-steel intracranial guide cannulae (C232GC; 22 gauge; Plastics One) with inserted dummy cannulae (C232DC) aimed at the DH (bilaterally; $1.7 \mathrm{~mm}$ posterior to bregma, $\pm 1.5 \mathrm{~mm}$ lateral to midline, $2.3 \mathrm{~mm}$ (injection site) ventral to skull surface). Guide cannulae were anchored to the skull with dental cement that also closed the wound. Mice recovered for at least $5 \mathrm{~d}$ before testing.

Drugs and infusions. During infusions, mice were gently restrained and dummy cannulae were replaced with injection cannulae (C232I; 28 gauge, extending $0.8 \mathrm{~mm}$ beyond the $1.5 \mathrm{~mm}$ guide) attached to polyeth- ylene tubing (PE50) connected to a $10 \mu \mathrm{l}$ Hamilton syringe. Infusions were controlled by microinfusion pump (KD Scientific), and were conducted at a rate of $0.5 \mu \mathrm{l} / \mathrm{min}$ for $1 \mathrm{~min}$. Infusion cannulae were left in place for another minute to prevent drug diffusion up the cannula track.

Cyclodextrin-encapsulated $17 \beta$-estradiol (Sigma) was dissolved in physiological saline to concentration of $10 \mu \mathrm{g} / \mu \mathrm{l}$, resulting in doses of 5 $\mu \mathrm{g} /$ side of the DH. Vehicle, 2-hydroxypropyl- $\beta$-cyclodextrin (HBC, Sigma), was dissolved in an equal volume of saline and contained the same amount of cyclodextrin as $\mathrm{E}_{2}$ for infusions. Garcinol (Enzo Life Sciences) was dissolved in $100 \%$ DMSO to a concentration of $2 \mu \mathrm{g} / \mathrm{ml}$, and then diluted to administer doses of $0.001,0.1,1$, and $10 \mu \mathrm{g} / \mathrm{side}$. Vehicles for each drug were based on their respective diluents. In studies where mice received two infusions into the $\mathrm{DH}$, DMSO vehicle or garcinol were always infused immediately before $\mathrm{HBC}$ vehicle or $\mathrm{E}_{2}$. For example, those infused with vehicle alone received both DMSO and HBC vehicles, those infused with $\mathrm{E}_{2}$ alone received DMSO vehicle immediately followed by $\mathrm{E}_{2}$, those infused with garcinol alone received garcinol followed immediately by $\mathrm{HBC}$ vehicle, and those infused with garcinol plus $\mathrm{E}_{2}$ received garcinol immediately followed by $\mathrm{E}_{2}$.

Object recognition. Novel object recognition, conducted as previously reported (Gresack et al., 2007), evaluated nonspatial hippocampal memory (Clark et al., 2000). Lesions or pharmacological inactivations of the DH block object recognition memory consolidation using this protocol (Clark et al., 2000; Baker and Kim, 2002; Fernandez et al., 2008). Briefly, mice were habituated to an empty white chamber by allowing them to freely explore for $5 \mathrm{~min}$ (no data were collected). After $24 \mathrm{~h}$, mice were rehabituated to the empty chamber for $1 \mathrm{~min}$ and then placed in a holding cage while two identical objects were placed near the left and right corners of the chamber. Mice were returned to the chamber for training and allowed to freely explore until they accumulated a total of $30 \mathrm{~s} \mathrm{ex-}$ ploring the objects (exploration recorded when the front paws or nose contacted the object). Mice were then removed from the chamber, immediately infused, and returned to their home cage. After 24 or $48 \mathrm{~h}$, object recognition was tested by substituting a novel object for a familiar training object (novel object location counterbalanced across mice). Time spent with each object was recorded; because mice inherently prefer to explore novel objects, a preference for the novel object (significantly more time than chance ( $15 \mathrm{~s}$ ) spent with the novel object) indicates intact memory for the familiar object. Vehicle-treated mice remember the familiar object after 24, but not $48 \mathrm{~h}$ (Gresack et al., 2007). Thus, a $24 \mathrm{~h}$ delay was used to observe memory impairing effects of garcinol and a 48 h delay was used to observe memory-enhancing effects of $E_{2}$.

Western blotting. Both dorsal hippocampi were dissected rapidly on dry ice either $30 \mathrm{~min}$ (for histones $\mathrm{H} 2 \mathrm{~B}, \mathrm{H} 3$, and $\mathrm{H} 4$ ) or $4 \mathrm{~h}$ (for the HDACs and DNMTs) after infusion. These time points were chosen based on our previous study showing that histone $\mathrm{H} 3$ acetylation in the dorsal hippocampus was increased by $\mathrm{E}_{2} 30 \mathrm{~min}$ after infusion, whereas HDAC2 and DNMT3B protein levels were not significantly altered until $4 \mathrm{~h}$ after infusion (Zhao et al., 2010). Samples were resuspended and sonicated in hypotonic lysis buffer. Total protein content of the lysates was measured by BCA protein assay (Thermo Scientific), sample buffer was added, and samples were boiled for $5 \mathrm{~min}$ at $100^{\circ} \mathrm{C}$. Samples were loaded onto $18 \%, 10 \%$, or $7.5 \%$ Tris- $\mathrm{HCl}$ polyacrylamide gels (Bio-Rad) for electrophoresis and, after separation, transferred to PVDF membranes (Millipore). Membranes were incubated overnight at $4^{\circ} \mathrm{C}$ with rabbit polyclonal or monoclonal antibodies recognizing acetylated histone H2B (Lys 12; 1:500, Cell Signaling Technology), acetylated histone H3 (Lys 9,14; 1:5000, Millipore), acetylated histone H4 (1:2000, Millipore), DNMT1 (1:500, Abcam), DNMT3A (1:1000, Cell Signaling Technology), DNMT3B (1:1000, Cell Signaling Technology), HDAC1 (1: 1000, Millipore), or HDAC2 (1:1000, Millipore). After TTBS wash, membranes were incubated for $1 \mathrm{~h}$ at room temperature with horseradish peroxidase-conjugated goat anti-rabbit IgG (Cell Signaling Technology) or with HRP-conjugated anti-mouse IgG (Sigma) and developed using enhanced chemiluminescence (SuperSignal West Dura, Thermo Scientific). Blots were then stripped for $1 \mathrm{~h}$ and reprobed with antibodies for total histone H2B (1:1000, Abcam), total histone H3 (1:5000, Millipore), total histone H4 (1:5000, Millipore) or monoclonal $\beta$-Actin (1: 5000 , Sigma) for normalization. Signal was detected using a Kodak Image 
Station 440CF and quantified by densitometry using Kodak 1D 3.6 software. Data were expressed as percent immunoreactivity relative to vehicle controls. Treatment effects were measured within single gels.

HAT activity assay. A colorimetric histone acetyltransferase activity assay kit from Abcam was used to measure nonspecific HAT activity. Acetylation of a peptide substrate by active HAT releases the free form of $\mathrm{CoA}$, which then serves as an essential coenzyme for producing $\mathrm{NADH}$ (Abcam). This kit detects NADH spectrophotometrically after it is reacted with a soluble tetrazolium dye. Both dorsal hippocampi were dissected rapidly on dry ice 5, 15, or 30 min after infusion. Samples were resuspended and sonicated in hypotonic lysis buffer. Total protein content of the lysates was measured by BCA protein assay. The lysates were diluted 1:2 and $40 \mu \mathrm{l}$ of this dilution were added to each well in duplicate in a U-shaped 96-well plate. To assess background HAT levels, a blank was added to the plate for each duplicate. Assay Mix ( $65 \mu \mathrm{l})$ was added to each well and plates were incubated at $37^{\circ} \mathrm{C}$ for $20 \mathrm{~min}$. Plates were read in a plate reader at $405 \mathrm{~nm}$, and blank values were subtracted from their corresponding duplicate.

Statistical analyses. Statistical analyses were conducted using SPSS 14.0 and GraphPad Prism 4.0. For each behavioral experiment, separate onesample $t$ tests were performed for each group to determine whether the time spent with the novel object differed from chance ( $15 \mathrm{~s})$. This analysis was used because time spent with the objects is not independent; time spent with one object reduces time spent with the other (Frick and Gresack, 2003). For Western blotting and HAT activity experiments including two groups, separate two-tailed unpaired Student's $t$ tests were performed between treatment and vehicle groups for each normalized protein. For Western blotting and HAT activity experiments including multiple groups, one-way ANOVAs were conducted, followed by Newman-Keuls post hoc tests. Significance was determined at $p<0.05$. Data were expressed as mean \pm SEM.

\section{Results}

\section{Histone acetylation is critical for $24 \mathrm{~h}$ object memory} consolidation in young ovariectomized mice

We first determined whether memory consolidation in the novel object recognition task requires histone acetylation. Mice were habituated to an empty testing arena by allowing them to freely explore for $15 \mathrm{~min}$. After $24 \mathrm{~h}$, mice were allowed to accumulate 30 s exploring two identical objects placed near the corners of the arena. Immediately after this training, mice received bilateral $\mathrm{DH}$ infusions of DMSO vehicle or one of four doses of garcinol (0.001, 0.1, 1 , and $10 \mu \mathrm{g} / \mathrm{side})$. Twenty-four hours later, mice were returned to the arena and allowed to accumulate $30 \mathrm{~s}$ exploring one novel object and one familiar object. Mice receiving vehicle spent significantly more time than chance (15s) with the novel object $\left(t_{(5)}=10.92, p<0.001\right.$; Fig. $\left.1 A\right)$, suggesting that they remembered the familiar object after $24 \mathrm{~h}$. This memory was dose-dependently impaired by garcinol. Garcinol at doses of 0.1 , 1 , and $10 \mu \mathrm{g} /$ side blocked memory consolidation; mice receiving these doses spent no more time than chance with the novel object, suggesting that histone acetylation is critical for $24 \mathrm{~h}$ object recognition memory consolidation.

\section{Histone acetylation is necessary for $E_{2}$ to enhance object memory consolidation}

In contrast to the $0.1,1$, and $10 \mu \mathrm{g} /$ side doses of garcinol, mice infused with $0.001 \mu \mathrm{g} / \mathrm{side}$ (hereafter referred to as $1 \mathrm{ng} / \mathrm{side}$ ) garcinol did show a preference for the novel object $\left(t_{(5)}=5.26\right.$, $p<0.01$; Fig. $1 A$ ), indicating that this dose did not block object recognition on its own. We then sought to coinfuse this subeffective dose with $\mathrm{E}_{2}$ at a longer $48 \mathrm{~h}$ delay to test the hypothesis that a dose of garcinol that does not block memory formation on its own can, nonetheless, block the beneficial effects of $\mathrm{E}_{2}$ on memory consolidation. As in our previous work with cell signaling inhibitors (Fernandez et al., 2008; Fan
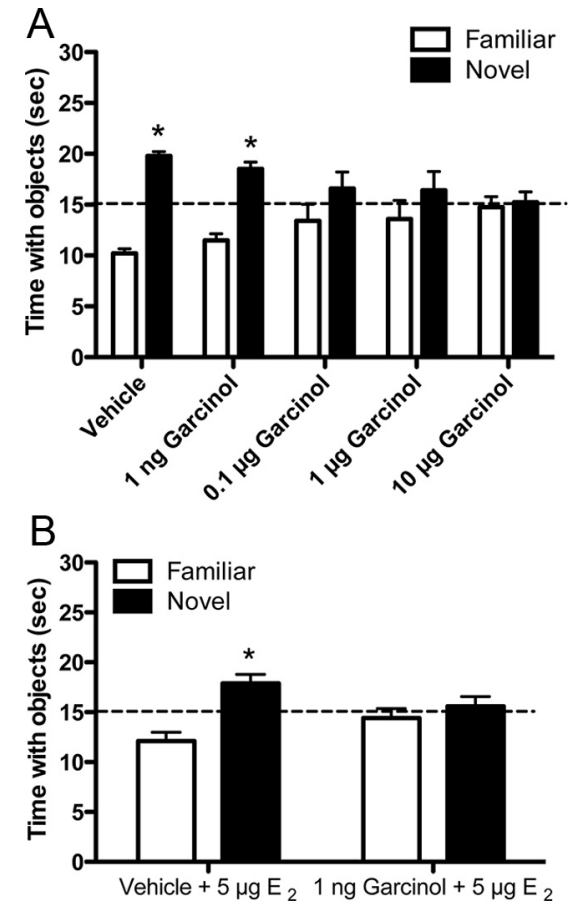

Figure 1. Garcinol blocked object recognition and the $E_{2}$-induced enhancement of object recognition. $A$, Mice received bilateral DH infusions of DMSO vehicle, or garcinol $(0.001,0.1,1$, or $10 \mu \mathrm{g} /$ side) immediately after object recognition training and were tested 24 h later ( $n=5-9 /$ group). Vehicle-treated mice spent significantly more time with the novel object than chance (dashed line at $15 \mathrm{~s} ;{ }^{*} p<0.05$ relative to chance), indicating intact memory for the familiar object at this delay. Garcinol in doses of $0.1,1$, or $10 \mu \mathrm{g} /$ side immediately after object recognition training spent no more time with the novel object than chance, indicating that these doses impaired object recognition memory consolidation. In contrast, mice receiving $0.001 \mu \mathrm{g} / \mathrm{side}$ (hereafter referred to as $1 \mathrm{ng} /$ side) garcinol significantly spent more time with the novel object than chance $\left({ }^{*} p<0.05\right.$ relative to chance), indicating that this dose of garcinol did not block memory on its own. As such, the $1 \mathrm{ng} /$ side dose was then used in all subsequent experiments to determine whether garcinol could block the behavioral and biochemical effects of $E_{2}$. $B$, Mice receiving bilateral $\mathrm{DH}$ infusion of DMSO vehicle $+5 \mu \mathrm{g} / \mathrm{side} \mathrm{E}_{2}(n=8)$ immediately after training spent significantly more time with the novel object than chance $48 \mathrm{~h}$ after infusion ( ${ }^{*} p<0.05$ relative to chance); this effect was blocked by concurrent infusion of garcinol ( $1 \mathrm{ng} / \mathrm{side} ; n=9$ ). Bars represent the mean \pm SEM time spent with each object.

et al., 2010; Zhao et al., 2010), the use of such a subeffective dose is necessary to ensure that any detrimental effects of garcinol on memory are not due to its ability to simply block general memory formation, but rather due to a specific blockade of the memory enhancing effects of $E_{2}$. We have previously shown that mice receiving $\mathrm{DH}$ infusions of $\mathrm{E}_{2}$, but not vehicle, spend significantly more time with the novel object than chance 48 h after infusion (Fernandez et al., 2008; Fan et al., 2010; Zhao et al., 2010). If histone acetylation is necessary for $\mathrm{E}_{2}$ to enhance object recognition, then we would expect garcinol to block the memory-enhancing effects of $E_{2}$. Therefore, another set of mice was behaviorally tested $48 \mathrm{~h}$ after bilateral $\mathrm{DH}$ infusion of DMSO vehicle plus $\mathrm{E}_{2}(5 \mu \mathrm{g} / \mathrm{side})$ or garcinol ( $1 \mathrm{ng} /$ side) plus $\mathrm{E}_{2}$. Mice receiving $\mathrm{E}_{2}$ alone spent significantly more time than chance $(15 \mathrm{~s})$ with the novel object $\left(t_{(7)}=3.30\right.$, $p<0.05$; Fig. $1 B$ ), indicating that they remembered the familiar object $48 \mathrm{~h}$ after infusion. In contrast, mice infused with garcinol plus $\mathrm{E}_{2}$ showed no preference for the novel object $\left(t_{(8)}=1.8424, p>0.05\right.$; Fig. $\left.1 B\right)$, suggesting that garcinol blocked the beneficial effects of $\mathrm{E}_{2}$ on object recognition. These data indicate that histone acetylation is necessary for $\mathrm{E}_{2}$ to enhance object recognition. 


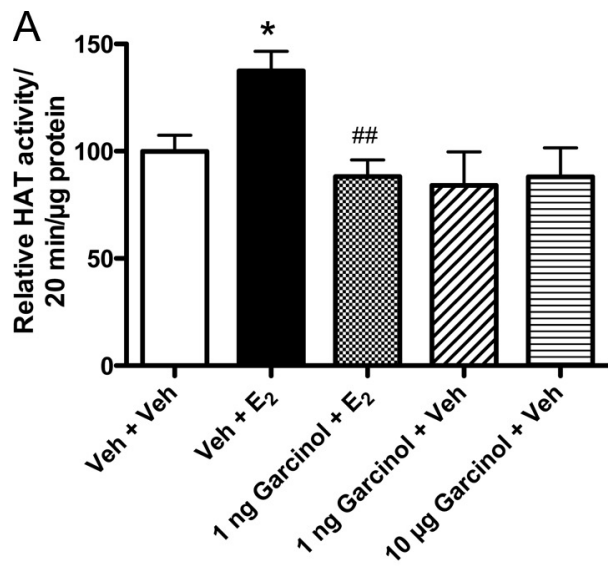

B

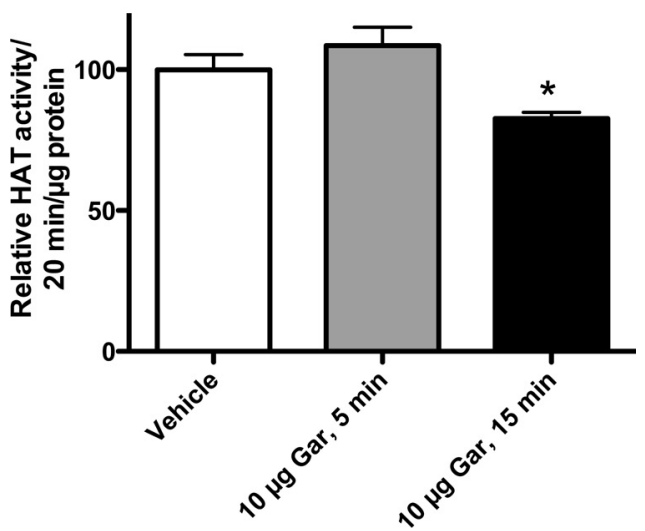

Figure 2. Garcinol reduced DH HAT activity and blocked the $E_{2}$-induced increase in DH HAT activity. $\boldsymbol{A}$, Mice received bilateral $\mathrm{DH}$ infusion of vehicle (Veh), vehicle $+5 \mu \mathrm{g} / \mathrm{side} \mathrm{E}_{2}, 1$ $\mathrm{ng} /$ side garcinol $+\mathrm{E}_{2}, 1 \mathrm{ng} / \mathrm{side}$ garcinol + vehicle, or $10 \mu \mathrm{g} / \mathrm{side}$ garcinol + vehicle $30 \mathrm{~min}$ before bilateral dissection of the DH $(n=5-7)$. $E_{2}$ significantly increased HAT activity $\left({ }^{*} p<\right.$ 0.05 relative to Veh), and this effect was reversed by $1 \mathrm{ng} /$ side garcinol ( ${ }^{\# \#} p<0.01$ relative to Veh $\left.+\mathrm{E}_{2}\right)$. Neither $1 \mathrm{ng} / \mathrm{side}$ nor $10 \mu \mathrm{g} /$ side garcinol altered HAT activity 30 min after infusion when administered with vehicle. $\boldsymbol{B}$, Relative to vehicle, $10 \mu \mathrm{g} / \mathrm{side}$ garcinol significantly reduced HAT activity $15 \mathrm{~min}\left({ }^{*} p<0.05\right)$, but not $5 \mathrm{~min}$, after infusion ( $n=4$ or 5 ). Bars represent mean \pm SEM percent change from vehicle (100\%).

\section{Garcinol prevented $\mathrm{E}_{2}$ from increasing dorsal hippocampal HAT activity and histone $\mathrm{H} 3$ acetylation}

The assumption underlying the above finding is that $\mathrm{E}_{2}$ enhances object recognition by increasing DH HAT activity, which then increases $\mathrm{H} 3$ acetylation. However, the effects of $\mathrm{E}_{2}$ on DH HAT activity have not previously been measured. In the event that $\mathrm{E}_{2}$ does increase HAT activity, we expected that the HAT inhibitor garcinol should block this increase. Therefore, we next examined whether HAT activity in the DH is affected by $\mathrm{E}_{2}$ or garcinol. A new set of mice received bilateral $\mathrm{DH}$ infusions consisting of vehicle, $5 \mu \mathrm{g} /$ side $\mathrm{E}_{2}, 1 \mathrm{ng} /$ side garcinol plus $\mathrm{E}_{2}, 1 \mathrm{ng} / \mathrm{side}$ garcinol, or $10 \mu \mathrm{g} / \mathrm{side}$ garcinol. Two doses of garcinol were administered to determine the effects on HAT activity of doses that had no effect ( $1 \mathrm{ng} / \mathrm{side}$ ) or impaired ( $10 \mu \mathrm{g} /$ side) object recognition regardless of $\mathrm{E}_{2}$ (Fig. $1 \mathrm{~A}$ ). HAT activity in the $\mathrm{DH}$ was measured 30 min after infusion, based on our previous observation that $E_{2}$ increases $\mathrm{H} 3$ acetylation 30 min after infusion (Zhao et al., 2010). A one-way ANOVA including all five groups revealed a significant main effect of treatment $\left(F_{(4,23)}=4.81 ; p=0.0058\right.$; Fig. $\left.2 A\right)$. Newman-Keuls post hoc tests showed that HAT activity was significantly increased after $\mathrm{E}_{2}$ infusion $\left({ }^{*} p<0.05\right.$ relative to vehicle; Fig. $2 A$ ), and this increase was blocked by concurrent infusion of $1 \mathrm{ng} /$ side garcinol ( $p<0.01$ relative to $\mathrm{E}_{2}$ alone; Fig. $2 A$ ). These data indicate that garcinol prevents $\mathrm{E}_{2}$ from increasing DH HAT activity. Interestingly, $1 \mathrm{ng} /$ side garcinol alone had no effect on HAT activity relative to vehicle, which is consistent with its inability to impair object recognition (Fig. 1A). Curiously, however, the $10 \mu \mathrm{g} / \mathrm{side}$ dose also had no effect on HAT activity $30 \mathrm{~min}$ after infusion $(p>0.05$ relative to vehicle; Fig. $2 A$ ). Given that garcinol can directly affect HAT activity (Balasubramanyam et al., 2004), whereas $\mathrm{E}_{2}$ 's effects on histone acetylation appear to be mediated by intermediaries like ERK (Zhao et al., 2010), we hypothesized that garcinol's inhibitory effect on HAT activity may occur earlier than $30 \mathrm{~min}$. Thus, we next gave a new set of mice a DH infusion of DMSO vehicle or $10 \mu \mathrm{g} /$ side garcinol, and dissected the DH 5 or 15 min later. HAT activity was significantly altered by garcinol infusion $\left(F_{(2,11)}=5.58 ; p=\right.$ 0.021 ; Fig. $2 B)$, such that activity was significantly reduced 15 $\mathrm{min}$, but not $5 \mathrm{~min}$, after infusion relative to vehicle ( $p<0.05$; the vehicle group consisted of mice killed at both time points). The reduction at $15 \mathrm{~min}$ is consistent with the fact that 10 $\mu \mathrm{g} /$ side garcinol impaired $24 \mathrm{~h}$ object recognition (Fig. $1 \mathrm{~A}$ ), and suggests that HAT activity regulates object recognition memory consolidation.

We next turned our attention to histone acetylation. We previously showed that $\mathrm{DH}$ infusion of $\mathrm{E}_{2}$ significantly increased acetylation of histone $\mathrm{H} 3$ (lys 9,14), but not histone $\mathrm{H} 4$ (lys 12) (Zhao et al., 2010). Because garcinol inhibited the $\mathrm{E}_{2}$-induced increase in $\mathrm{HAT}$ activity, it should prevent $\mathrm{E}_{2}$ from increasing $\mathrm{H} 3$ acetylation. Therefore, we next tested a new set of mice receiving bilateral $\mathrm{DH}$ infusions of vehicle alone, $5 \mu \mathrm{g} / \mathrm{side}_{\mathrm{E}} \mathrm{E}_{2}$ alone, 1 $\mathrm{ng} /$ side garcinol alone, or $1 \mathrm{ng} /$ side garcinol plus $\mathrm{E}_{2}$ as above. Thirty minutes after infusion, mice were killed and the DH dissected bilaterally to assay histone $\mathrm{H} 2 \mathrm{~B}$ (Lys 12), histone $\mathrm{H} 3$ (Lys 9,14 ), and $\mathrm{H} 4$ (lys 12) acetylation. One-way ANOVA revealed a significant treatment effect for acetyl $\mathrm{H} 3\left(F_{(3,18)}=4.30, p=0.02\right.$; Fig. $3 A)$, but not acetyl $\mathrm{H} 2 \mathrm{~B}\left(F_{(3,12)}=0.69, p=0.58\right.$; Fig. $\left.3 B\right)$ or acetyl $\mathrm{H} 4\left(F_{(3,17)}=0.85, p=0.49\right.$; Fig. $\left.3 C\right)$. DH histone H3 acetylation was increased $30 \mathrm{~min}$ after $\mathrm{E}_{2}$ infusion relative to vehicle $(p<0.05)$, and this increase was reversed by DH infusion of garcinol ( $p<0.05$ relative to $\mathrm{E}_{2}$ alone; Fig. $\left.3 A\right)$. Garcinol alone had no effect on $\mathrm{H} 3$ acetylation. Although a similar pattern of results was observed for histone $\mathrm{H} 2 \mathrm{~B}$, the groups did not significantly differ. Together, these data show that inhibition of HAT activity in the $\mathrm{DH}$ by garcinol can block the $\mathrm{E}_{2}$-induced increase in DH HAT activity and histone H3 acetylation. This finding strongly supports the notion that histone acetylation, mediated by HAT enzymes, is critical for $\mathrm{E}_{2}$ to enhance object recognition memory consolidation.

\section{Garcinol blocked the $\mathrm{E}_{2}$-induced decrease in dorsal hippocampal HDAC2 protein expression}

We next examined whether garcinol could prevent $\mathrm{E}_{2}$ from altering the expression of HDAC proteins. HDAC activity and histone deacetylation have been associated with transcriptional repression (Narlikar et al., 2002). We have previously shown that $\mathrm{E}_{2}$ significantly decreases protein levels of HDAC2 in the DH $4 \mathrm{~h}$ after infusion (Zhao et al., 2010). In contrast, levels of HDAC1 protein were not altered by $\mathrm{E}_{2} 1-4 \mathrm{~h}$ after infusion (Zhao et al., 2010). Both HDACs are expressed in the adult mouse hippocampus, where HDAC1 is expressed primarily in glia and neural progenitor cells, and HDAC2 is expressed in neurons and neural progenitor cells (MacDonald and Roskams, 2008). In adult mice, HDAC1 regulates cell proliferation and differentiation (Kim et al., 2008), and HDAC2, but not HDAC1, negatively modulates 

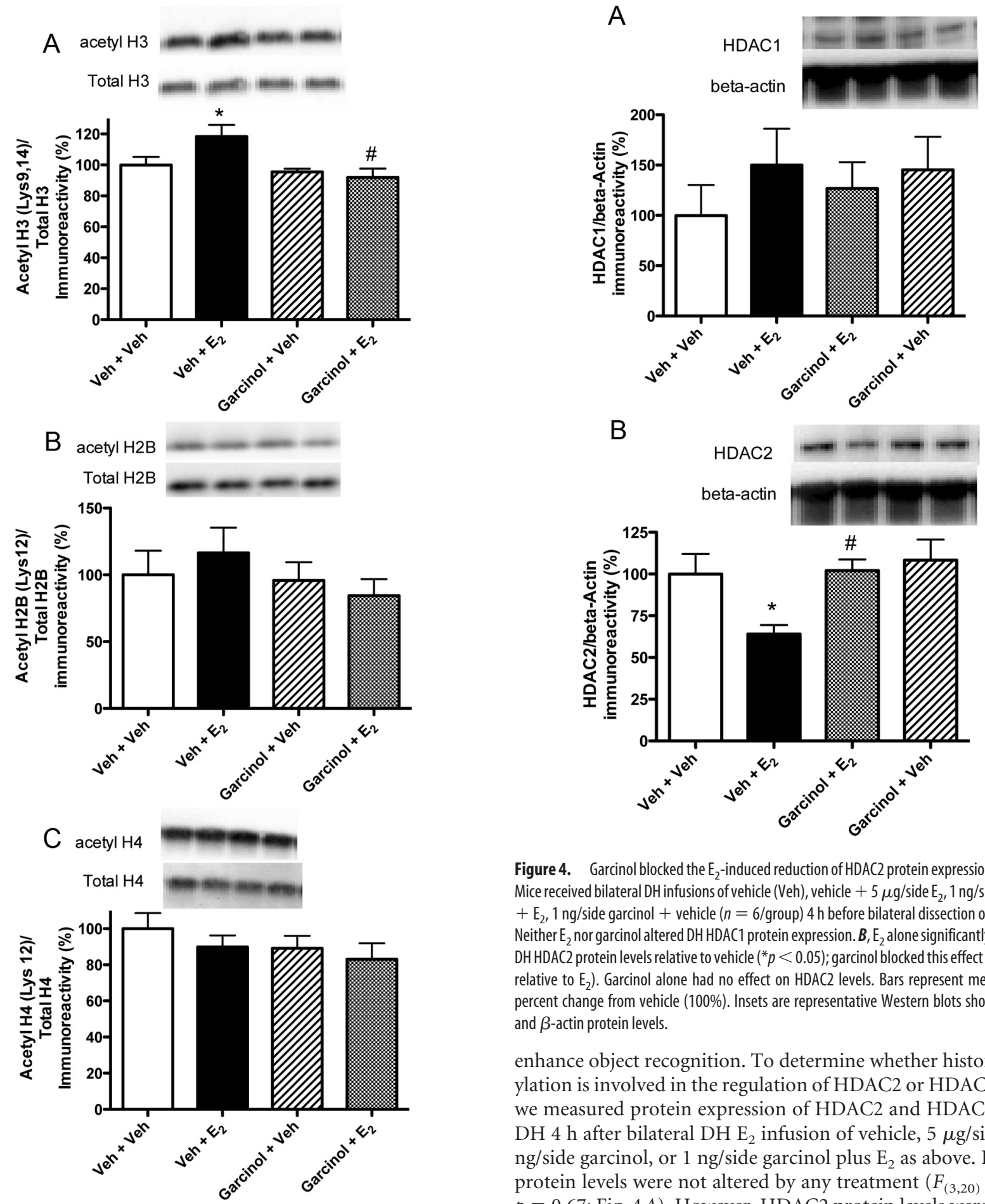

Figure 3. Garcinol blocked $\mathrm{E}_{2}$-induced histone $\mathrm{H} 3$ acetylation in the $\mathrm{DH}$. Mice received bilateral DH infusions of vehicle (Veh), vehicle $+5 \mu \mathrm{g} /$ side $\mathrm{E}_{2}, 1 \mathrm{ng} /$ side garcinol + vehicle, or 1 $\mathrm{ng} /$ side garcinol $+\mathrm{E}_{2}$ ( $n=5$ or 6/group) 30 min before bilateral dissection of the DH. $A_{1} E_{2}$ alone significantly increased DH histone $\mathrm{H} 3($ Lys 9,14$)$ acetylation relative to vehicle $\left({ }^{*} p<\right.$ $0.05)$; garcinol blocked this effect ( ${ }^{\#} p<0.05$ relative to $E_{2}+$ Veh). $\boldsymbol{B}$, Neither $E_{2}$ nor garcinol significantly altered $\mathrm{DH} \mathrm{H} 2 \mathrm{~B}$ acetylation. $C_{\text {, Neither }} \mathrm{E}_{2}$ nor garcinol significantly altered $\mathrm{DH} \mathrm{H}_{4}$ acetylation. Bars represent mean \pm SEM percent change from vehicle (100\%). Insets are representative Western blots showing acetylated and total $\mathrm{H} 2 \mathrm{~B}, \mathrm{H} 3$, and $\mathrm{H} 4$ protein levels.

hippocampal memory and synaptic plasticity (Guan et al., 2009). Our observation that $\mathrm{E}_{2}$ can decrease levels of HDAC2 protein (Zhao et al., 2010) suggests that an $\mathrm{E}_{2}$-induced reduction of this memory repressor protein may contribute to the ability of $\mathrm{E}_{2}$ to

Figure 4. Garcinol blocked the $\mathrm{E}_{2}$-induced reduction of $\mathrm{HDAC} 2$ protein expression in the $\mathrm{DH}$. Mice received bilateral DH infusions of vehicle (Veh), vehicle $+5 \mu \mathrm{g} / \mathrm{side}_{2}, 1 \mathrm{ng} / \mathrm{side}$ garcinol $+\mathrm{E}_{2}, 1 \mathrm{ng} /$ side garcinol + vehicle $(n=6 /$ group $) 4 \mathrm{~h}$ before bilateral dissection of the $\mathrm{DH} . \boldsymbol{A}$, Neither $E_{2}$ nor garcinol altered DH HDAC1 protein expression. $\boldsymbol{B}, \mathrm{E}_{2}$ alone significantly decreased DH HDAC2 protein levels relative to vehicle $\left({ }^{*} p<0.05\right)$; garcinol blocked this effect $\left({ }^{*} p<0.05\right.$ relative to $\left.E_{2}\right)$. Garcinol alone had no effect on HDAC2 levels. Bars represent mean \pm SEM percent change from vehicle (100\%). Insets are representative Western blots showing HDAC and $\beta$-actin protein levels.

enhance object recognition. To determine whether histone acetylation is involved in the regulation of HDAC2 or $\mathrm{HDAC} 1$ by $\mathrm{E}_{2}$, we measured protein expression of HDAC2 and HDAC1 in the $\mathrm{DH} 4 \mathrm{~h}$ after bilateral $\mathrm{DH} \mathrm{E}_{2}$ infusion of vehicle, $5 \mu \mathrm{g} / \mathrm{side}_{2}, 1$ $\mathrm{ng} /$ side garcinol, or $1 \mathrm{ng} /$ side garcinol plus $\mathrm{E}_{2}$ as above. $\mathrm{HDAC} 1$ protein levels were not altered by any treatment $\left(F_{(3,20)}=0.52\right.$, $p=0.67$; Fig. $4 A$ ). However, HDAC2 protein levels were significantly affected by treatment $\left(F_{(3,20)}=4.32, p=0.017\right.$; Fig. $\left.4 B\right)$. Levels were significantly decreased by $\mathrm{E}_{2}(p<0.05$ relative to vehicle), and this effect was blocked by concurrent infusion of garcinol $\left(p<0.05\right.$ garcinol plus $\mathrm{E}_{2}$ group relative to the $\mathrm{E}_{2}+$ Veh group; Fig. $4 B)$. Garcinol (1 ng/side) alone had no effect on HDAC2 protein expression (Fig. $4 B$ ). These results suggest that the $\mathrm{E}_{2}$-induced reduction in HDAC2 levels are mediated by histone acetylation, perhaps through an increase in DNA methylation (see below).

Garcinol blocked the $\mathrm{E}_{2}$-induced increase in dorsal

hippocampal DNMT3B protein expression

Finally, we considered whether histone acetylation affects the other major epigenetic alteration that has been associated with learning 
A

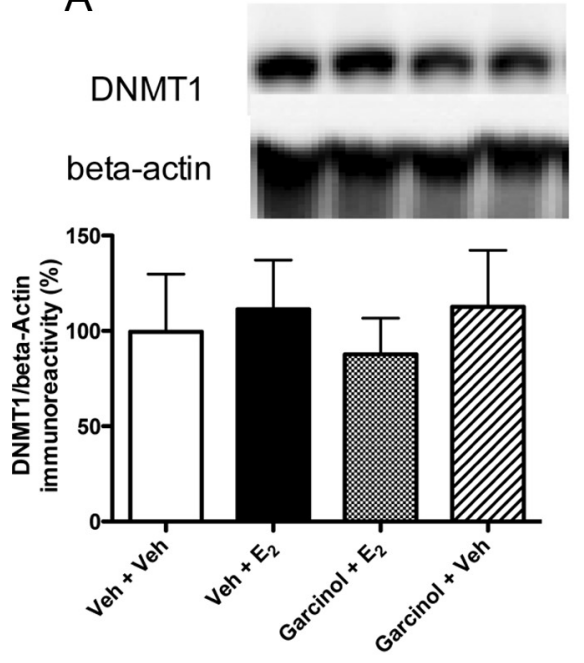

B
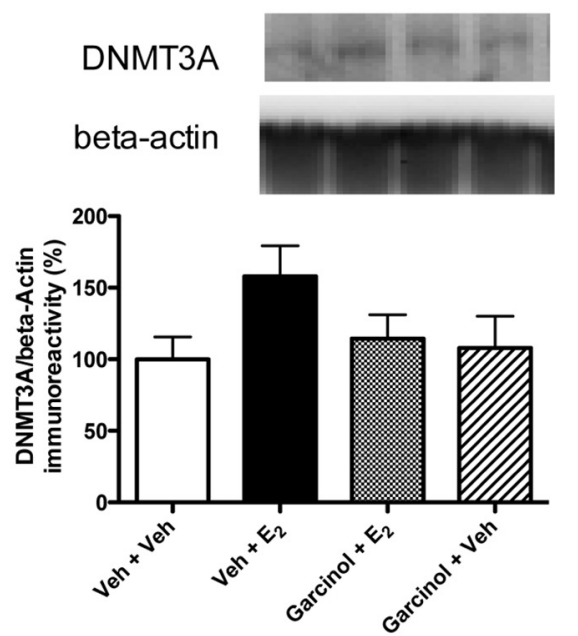

C

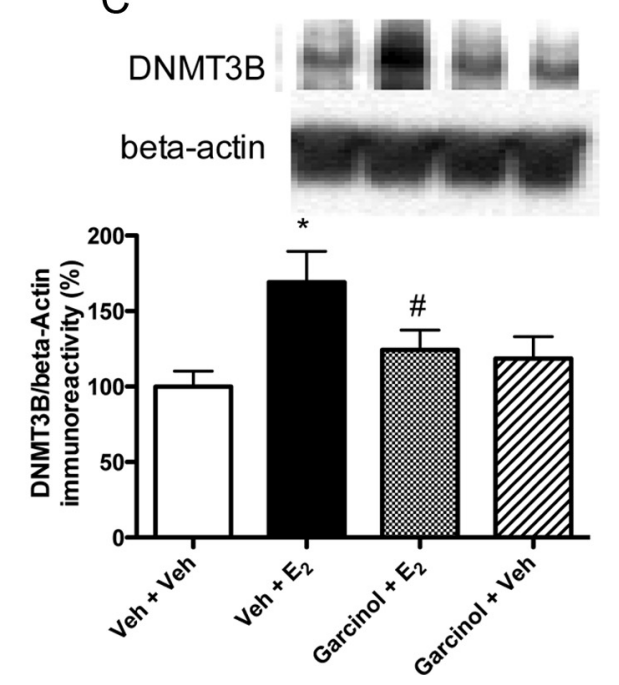

Figure 5. Garcinol blocked the $E_{2}$-induced increase of DNMT3B protein expression in the DH. Mice received bilateral DH infusions of vehicle (Veh), vehicle $+5 \mu \mathrm{g} /$ side $E_{2}, 1 \mathrm{ng} /$ side garcinol $+E_{2}$, or $1 \mathrm{ng} /$ side garcinol + vehicle $(n=4-6 /$ group $) 4 \mathrm{~h}$ before bilateral dissection of the DH. $\boldsymbol{A}, \boldsymbol{B}$, Neither $\mathrm{E}_{2}$ nor garcinol altered DH DNMT1 or DNMT3A protein expression. $\boldsymbol{C}_{,} \mathrm{E}_{2}$ alone significantly increased DH DNMT3B protein levels relative to vehicle $\left({ }^{*} p<0.05\right)$, and garcinol blocked this effect $\left({ }^{\#} p<0.05\right.$ relative to $E_{2}+$ Veh). Bars represent mean \pm SEM percent change from vehicle (100\%). Insets are representative Western blots showing DNMT and $\beta$-actin protein levels.

and memory, DNA methylation (Levenson et al., 2006; Miller and Sweatt, 2007). The methylation of DNA at cytosine residues typically silences gene transcription, although the functional consequences of this silencing depend on the specific genes altered. Methylation is catalyzed by the DNA (cytosine- $5^{\prime}$ ) methyltransferase (DNMT) enzymes DNMT1, DNMT3A, and DNMT3B. DNMT1 is a maintenance methyltransferase, responsible for copying methylation to nascent DNA strands during replication, whereas DNMT3A and DNMT3B are de novo methyltransferases that add new methyl residues to DNA (Bird, 2002; Li, 2002). Like histone acetylation, DNA methylation plays a critical role in hippocampal memory consolidation (Levenson et al., 2006; Miller and Sweatt, 2007), and both processes are thought to work in concert to dynamically regulate memory formation and synaptic plasticity (Miller et al., 2008). We previously showed that a DNMT inhibitor blocked the beneficial effects of $E_{2}$ on object recognition, and that $E_{2}$ increased expression of DNMT3B mRNA and protein $45 \mathrm{~min}$ and $4 \mathrm{~h}$ after infusion, respectively (Zhao et al., 2010). As such, it was of interest here to examine whether histone acetylation plays a role in regulating DNMT levels. We measured protein expression of DNMT1, DNMT3A, and DNMT3B in the $\mathrm{DH} 4 \mathrm{~h}$ after bilateral $\mathrm{DH}_{2}$ infusion of vehicle, $5 \mu \mathrm{g} /$ side $\mathrm{E}_{2}, 1 \mathrm{ng} / \mathrm{side}$ garcinol, or 1 ng/side garcinol plus $\mathrm{E}_{2}$ as above. DNMT1 protein levels were not altered by these treatments $\left(F_{(3,15)}=0.21, p=0.89\right.$; Fig. $\left.5 A\right)$. Although DNMT3A protein levels tended to increase after $\mathrm{E}_{2}$ infusion (Fig. $5 B$ ), there was no significant treatment effect observed in the $\operatorname{ANOVA}\left(F_{(3,19)}=1.70, p=0.20\right)$. However, DNMT3B protein expression was significantly affected by treatment $\left(F_{(3,18)}=3.92, p=0.026\right.$; Fig. $\left.5 C\right)$; levels were increased $4 \mathrm{~h}$ after infusion of $\mathrm{E}_{2}$ $(p<0.05$ relative to vehicle), and this effect was blocked by garcinol $(p<0.05$ relative to $\mathrm{E}_{2}$ alone). These data indicate that histone acetylation is necessary for $\mathrm{E}_{2}$ to increase DNMT3B expression, and support the notion that DNA methylation and histone acetylation works synergistically to regulate the mnemonic effects of $\mathrm{E}_{2}$.

\section{Discussion}

Recent studies using HDAC inhibitors or genetic alterations of HATs have demonstrated that histone acetylation can regulate hippocampal memory formation (Alarcón et al., 2004; Levenson et al., 2004; Wood et al., 2006; Fischer et al., 2007; Oliveira et al., 2007; Vecsey et al., 2007; Stefanko et al., 2009; Zhao et al., 2010). The present study extends this work by providing the first demonstration that a HAT inhibitor, infused directly into the $\mathrm{DH}$, can both inhibit hippocampal memory consolidation and block the memoryenhancing effects of a modulatory steroid hormone. Three doses of garcinol $(0.1,1$, and $10 \mu \mathrm{g} /$ side) impaired $24 \mathrm{~h}$ object recognition, suggesting that histone acetylation is critical for object memory consolidation. In contrast, $1 \mathrm{ng} /$ side garcinol had no effect on object recognition, and therefore, was insufficient to block memory formation. Although this dose alone did not affect HAT activity 30 min after infusion, it may have affected HAT activity at other time points. The $10 \mu \mathrm{g} /$ side dose significantly reduced HAT activity $15 \mathrm{~min}$ after infusion, suggesting that HAT activity is critical for memory formation, although this association must be tested more rigorously with various doses and time points. Nevertheless, the fact that $10 \mu \mathrm{g} /$ side garcinol can reduce DH HAT activity is consistent with previous in vitro studies showing that $1-10 \mu \mathrm{M}$ garcinol inhibits p300 and PCAF activity on purified HeLa core histones (Balasubramanyam et al., 2004; Arif et al., 2009). Garcinol's memory impairing effects contrast appropriately with the memory enhancing effects of HDAC inhibitors, such as trichostatin-A (TSA) and sodium butyrate (NaB), which increase hippocampal histone $\mathrm{H} 3$ and $\mathrm{H} 4$ acetylation, enhance hippocampal long-term potentiation, and promote contextual 
fear conditioning and spatial memory in the Morris water maze (Levenson et al., 2004; Fischer et al., 2007; Vecsey et al., 2007). Other HDAC inhibitors have reversed contextual fear and spatial memory deficits in transgenic mouse models of Alzheimer's disease (Ricobaraza et al., 2009). Of particular note for the present study is the fact that TSA and $\mathrm{NaB}$ enhance object recognition in wild-type and CBP mutant mice (Stefanko et al., 2009; Zhao et al., 2010), suggesting that inhibition of HDAC activity, thereby increasing histone acetylation, facilitates long-term object recognition. As such, inhibition of HAT activity, thereby reducing histone acetylation, should impair object recognition, as was seen here and in previous studies of mice expressing truncated forms of p300 and CBP (Alarcón et al., 2004; Wood et al., 2006; Oliveira et al., 2007). Together, these data suggest that histone acetylation is a critical modulator of object recognition memory consolidation.

Although several HAT inhibitor drugs have been synthesized, none were previously administered in vivo to examine their effects on cognitive function. Several, like Lys-CoA, H3 Co-A20, and anacardic acid, have poor cell-membrane permeability (Mantelingu et al., 2007), and thus, are not suitable candidates for in vivo use. However, the cell-permeable garcinol is a nonspecific HAT inhibitor, so it is unclear which HATs are critical for its behavioral effects. Garcinol is potent inhibitor of p300/CBP and PCAF in vitro (Balasubramanyam et al., 2004; Arif et al., 2009), suggesting the potential involvement of multiple HATs in object recognition. In vitro studies find that garcinol is a more efficient inhibitor for PCAF than p300/CPB, and has a higher affinity for PCAF (Balasubramanyam et al., 2004). Further, PCAF primarily acetylates $\mathrm{H} 3$, so perhaps PCAF is more significant in the effects of garcinol than p300/CBP. However, studies of transgenic p300 and CBP mice demonstrate a role for these HATs in regulating object recognition memory (Wood et al., 2006; Oliveira et al., 2007; Stefanko et al., 2009). As such, studies using more specific HAT inhibitors must be conducted to pinpoint which HATs are critical for memory formation and the modulation of memory by $E_{2}$. One such drug, LTK-14, which is specific for p300, might be a suitable candidate (Mantelingu et al., 2007). Such information is important not only to advance our understanding of the neurobiology of learning and memory, but also to characterize the potential cognitive effects of HAT inhibitors under development to treat cancer, diabetes, AIDS, or other conditions. Garcinol inhibits cell proliferation and survival in colon and breast cancer cells (Hong et al., 2007; Ahmad et al., 2010), so could be a useful anti-proliferative treatment for various cancers. However, if the present garcinol-induced memory impairment generalizes to other types of memory, then cognitive side effects should be considered when evaluating the therapeutic potential of garcinol, or other HAT inhibitors, to treat disease.

The fact that the $1 \mathrm{ng} /$ side dose of garcinol blocked the effects of intrahippocampally infused $\mathrm{E}_{2}$ on object recognition and histone $\mathrm{H} 3$ acetylation suggests that histone acetylation is necessary for $E_{2}$ to enhance object recognition memory consolidation. The present findings that $\mathrm{E}_{2}$ increased $\mathrm{H} 3$, but not $\mathrm{H} 4$, acetylation 30 min after infusion, and altered protein expression of HDAC2 and DNMT3B, but not HDAC1, DNMT1, and DNMT3A, $4 \mathrm{~h}$ after infusion replicates our previous findings (Zhao et al., 2010). The fact that a behaviorally subeffective dose of garcinol blocked these effects suggests a specific interaction between $\mathrm{E}_{2}$ and garcinol that prevented $\mathrm{E}_{2}$ induced alterations. The garcinol-induced blockade of $\mathrm{E}_{2}$ stimulated $\mathrm{H} 3$ acetylation is entirely consistent with the fact that garcinol prevents $\mathrm{E}_{2}$ from increasing HAT activity. The lack of effect of $\mathrm{E}_{2}$ on $\mathrm{H} 4$ acetylation is also consistent with previous findings from our lab (Zhao et al., 2010) and studies showing no effect of contextual fear learning on H4 (Levenson et al., 2004). Interestingly, H4 is more sensitive to garcinol than $\mathrm{H} 3$ in vitro (Balasubramanyam et al., 2004), so it is perhaps surprising that garcinol alone did not affect $\mathrm{H} 4$ acetylation. However, we did not examine whether behaviorally effective doses of garcinol, like $10 \mu \mathrm{g} / \mathrm{side}$, could affect histone acetylation, so we cannot exclude that $\mathrm{H} 3$ or $\mathrm{H} 4$ acetylation may be reduced in response to a higher dose. Furthermore, it is possible that $\mathrm{H} 4$ lysine residues other than Lys 12 may be affected by $\mathrm{E}_{2}$, so we cannot yet rule out any effects of $\mathrm{E}_{2}$ on $\mathrm{H} 4$ acetylation. Likewise, $\mathrm{H} 2 \mathrm{~B}$ acetylation at Lys 12 was also not significantly affected by $\mathrm{E}_{2}$ or $1 \mathrm{ng}$ of garcinol, but other doses of these drugs and other lysine residues must be examined before concluding that $\mathrm{H} 2 \mathrm{~B}$ acetylation is not affected by $\mathrm{E}_{2}$ or garcinol, particularly given recent data showing that $\mathrm{CBP}$ is critical for acetylation of dorsal hippocampal histones $\mathrm{H} 2 \mathrm{~B}$, H3, and H4 (Barrett et al., 2011).

The lack of effect of $\mathrm{E}_{2}$ and garcinol on $\mathrm{HDACl}$ expression is consistent with our previous in vivo $\mathrm{E}_{2}$ findings (Zhao et al., 2010) and with a null effect of garcinol on HDAC1 in HeLa cells (Balasubramanyam et al., 2004). Here, we replicate our previous report of an $\mathrm{E}_{2}$-induced reduction in HDAC2 expression (Zhao et al., 2010), and the fact that garcinol blocked this effect extends this finding to suggest that histone acetylation plays a role in this reduction. HDAC3 has also recently been shown to impair hippocampal memory (McQuown et al., 2011), so the effects of $\mathrm{E}_{2}$ and garcinol on this important protein should be examined in future studies. HDAC2 is a potent negative modulator of hippocampal memory and plasticity (Guan et al., 2009), so the present data suggest that $\mathrm{E}_{2}$ may regulate object recognition, at least in part, by reducing dorsal hippocampal HDAC2 expression. Hippocampal histone acetylation can also be regulated by DNMT activity, as demonstrated by the fact that intrahippocampal infusion of the DNMT inhibitor 5-aza-2deoxycytidine (5-AZA) blocks hippocampal H3 acetylation and impairs contextual fear conditioning (Miller et al., 2008). We have previously shown that 5-AZA also blocks $\mathrm{E}_{2}$-induced enhancement of object recognition, and that $\mathrm{E}_{2}$ increases expression of DNMT3B (Zhao et al., 2010). Thus, we have proposed that DNA methylation, specifically de novo methylation, is critical to the memory-enhancing effects of $E_{2}$, and have hypothesized that the $E_{2}$-induced regulation of HDAC2 may occur via DNA methylation, possibly related to the increase in DNMT3B (Zhao et al., 2010). With the present data, we further speculate that $\mathrm{E}_{2}$-induced acetylation of histone acetylation increases expression of DNMT3B, which then silences HDAC2 through de novo methylation. Although an attractive hypothesis, chromatin immunoprecipitation analysis of DNMT3B and methylation analyses of HDAC2 in response to $\mathrm{E}_{2}$ will be necessary to test this idea. Other potential memory-repressor proteins that may be methylated by $\mathrm{E}_{2}$ are $\mathrm{HDAC} 3$ and $\mathrm{PP} 1$, the latter of which impairs hippocampal memory processing and is repressed by DNA methylation (Miller and Sweatt, 2007).

In conclusion, the present study provides the first evidence that a HAT inhibitor can regulate memory and block the memoryenhancing effects of $E_{2}$. These data are consistent with a growing literature demonstrating that histone acetylation is critical for hippocampal memory formation. As such increasing histone acetylation through treatments such as $\mathrm{E}_{2}$ (Zhao et al., 2010), environmental enrichment (Fischer et al., 2007), or HDAC inhibitors (Levenson et al., 2004), may be especially useful for the treatment of various disorders characterized by memory impairment.

\section{References}

Ahmad A, Wang Z, Ali R, Maitah MY, Kong D, Banerjee S, Padhye S, Sarkar FH (2010) Apoptosis-inducing effect of garcinol is mediated by NFkappaB signaling in breast cancer cells. J Cell Biochem 109:1134-1141.

Alarcón JM, Malleret G, Touzani K, Vronskaya S, Ishii S, Kandel ER, Barco A (2004) Chromatin acetylation, memory, and LTP are impaired in 
CBP +/ - mice: a model for the cognitive deficit in Rubinstein-Taybi syndrome and its amelioration. Neuron 42:947-959.

Arif M, Pradhan SK, Thanuja GR, Vedamurthy BM, Agrawal S, Dasgupta D, Kundu TK (2009) Mechanism of p300 specific histone acetyltransferase inhibition by small molecules. J Med Chem 52:267-277.

Baker KB, Kim JJ (2002) Effects of stress and hippocampal NMDA receptor antagonism on recognition memory in rats. Learn Mem 9:58-65.

Balasubramanyam K, Altaf M, Varier RA, Swaminathan V, Ravindran A, Sadhale PP, Kundu TK (2004) Polyisoprenylated benzophenone, garcinol, a natural histone acetyltransferase inhibitor, represses chromatin transcription and alters global gene expression. J Biol Chem 279:33716-33726.

Barrett RM, Malvaez M, Kramar E, Matheos DP, Arrizon A, Cabrera SM, Lynch G, Greene RW, Wood MA (2011) Hippocampal focal knockout of CBP affects specific histone modifications, long-term potentiation, and long-term memory. Neuropsychopharmacology 36:1545-1556.

Bird A (2002) DNA methylation patterns and epigenetic memory. Genes Dev 16:6-21.

Clark RE, Zola SM, Squire LR (2000) Impaired recognition memory in rats after damage to the hippocampus. J Neurosci 20:8853-8860.

Dal Piaz F, Tosco A, Eletto D, Piccinelli AL, Moltedo O, Franceschelli S, Sbardella G, Remondelli P, Rastrelli L, Vesci L, Pisano C, De Tommasi N (2010) The identification of a novel natural activator of p300 histone acetyltransferase provides new insights into the modulation mechanism of this enzyme. Chembiochem 11:818-827.

Duclot F, Jacquet C, Gongora C, Maurice T (2010) Alteration of working memory but not in anxiety or stress response in p300/CBP associated factor (PCAF) histone acetylase knockout mice bred on a C57BL/6 background. Neurosci Lett 475:179-183.

Fan L, Zhao Z, Orr PT, Chambers CH, Lewis MC, Frick KM (2010) Estradiol-induced object memory consolidation in middle-aged female mice requires dorsal hippocampal extracellular signal-regulated kinase and phosphatidylinositol 3-kinase activation. J Neurosci 30:4390-4400.

Fernandez SM, Lewis MC, Pechenino AS, Harburger LL, Orr PT, Gresack JE, Schafe GE, Frick KM (2008) Estradiol-induced enhancement of object memory consolidation involves hippocampal ERK activation and membrane-bound estrogen receptors. J Neurosci 28:8660-8667.

Fischer A, Sananbenesi F, Wang X, Dobbin M, Tsai LH (2007) Recovery of learning and memory is associated with chromatin remodelling. Nature 447:178-182.

Frick KM, Gresack JE (2003) Sex differences in the behavioral response to spatial and object novelty in adult C57BL/6 mice. Behav Neurosci 117:1283-1291.

Gresack JE, Kerr KM, Frick KM (2007) Life-long environmental enrichment differentially affects the mnemonic response to estrogen in young, middle-aged, and aged female mice. Neurobiol Learn Mem 88:393-408.

Guan JS, Haggarty SJ, Giacometti E, Dannenberg JH, Joseph N, Gao J, Nieland TJ, Zhou Y, Wang X, Mazitschek R, Bradner JE, DePinho RA, Jaenisch R, Tsai LH (2009) HDAC2 negatively regulates memory formation and synaptic plasticity. Nature 459:55-60.

Haettig J, Stefanko DP, Multani ML, Figueroa DX, McQuown SC, Wood MA (2011) HDAC inhibition modulates hippocampus-dependent long-term memory for object location in a CBP-dependent manner. Learn Mem 18:71-79.

Hong J, Kwon SJ, Sang S, Ju J, Zhou JN, Ho CT, Huang MT, Yang CS (2007) Effects of garcinol and its derivatives on intestinal cell growth: inhibitory effects and autoxidation-dependent growth-stimulatory effects. Free Radic Biol Med 42:1211-1221.

Kilgore M, Miller CA, Fass DM, Hennig KM, Haggarty SJ, Sweatt JD, Rumbaugh G (2010) Inhibitors of class 1 histone deacetylases reverse contextual memory deficits in a mouse model of Alzheimer's disease. Neuropsychopharmacology 35:870-880.

Kim D, Frank CL, Dobbin MM, Tsunemoto RK, Tu W, Peng PL, Guan JS, Lee BH, Moy LY, Giusti P, Broodie N, Mazitschek R, Delalle I, Haggarty SJ, Neve RL, Lu Y, Tsai LH (2008) Deregulation of HDAC1 by p25/Cdk5 in neurotoxicity. Neuron 60:803-817.

Korzus E, Rosenfeld MG, Mayford M (2004) CBP histone acetyltransferase activity is a critical component of memory consolidation. Neuron 42:961-972.

Levenson JM, O’Riordan KJ, Brown KD, Trinh MA, Molfese DL, Sweatt JD (2004) Regulation of histone acetylation during memory formation in the hippocampus. J Biol Chem 279:40545-40559.

Levenson JM, Roth TL, Lubin FD, Miller CA, Huang IC, Desai P, Malone LM, Sweatt JD (2006) Evidence that DNA (Cytosine-5) methyltransferase regulates synaptic plasticity in the hippocampus. J Biol Chem 281:15763-15773.
Li E (2002) Chromatin modification and epigenetic reprogramming in mammalian development. Nat Rev Genet 3:662-673.

Liao CH, Ho CT, Lin JK (2005a) Effects of garcinol on free radical generation and NO production in embryonic rat cortical neurons and astrocytes. Biochem Biophys Res Commun 329:1306-1314.

Liao CH, Sang S, Ho CT, Lin JK (2005b) Garcinol modulates tyrosine phosphorylation of FAK and subsequently induces apoptosis through downregulation of Src, ERK, and Akt survival signaling in human colon cancer cells. J Cell Biochem 96:155-169.

Luger K, Mäder AW, Richmond RK, Sargent DF, Richmond TJ (1997) Crystal structure of the nucleosome core particle at 2.8 A resolution. Nature 389:251-260.

MacDonald JL, Roskams AJ (2008) Histone deacetylases 1 and 2 are expressed at distinct stages of neuro-glial development. Dev Dyn 237:2256-2267.

Mantelingu K, Reddy BA, Swaminathan V, Kishore AH, Siddappa NB, Kumar GV, Nagashankar G, Natesh N, Roy S, Sadhale PP, Ranga U, Narayana C, Kundu TK (2007) Specific inhibition of p300-HAT alters global gene expression and represses HIV replication. Chem Biol 14:645-657.

Maurice T, Duclot F, Meunier J, Naert G, Givalois L, Meffre J, Célérier A, Jacquet C, Copois V, Mechti N, Ozato K, Gongora C (2008) Altered memory capacities and response to stress in p300/CBP-associated factor (PCAF) histone acetylase knockout mice. Neuropsychopharmacology 33:1584-1602.

McQuown SC, Barrett RM, Matheos DP, Post RJ, Rogge GA, Alenghat T, Mullican SE, Jones S, Rusche JR, Lazar MA, Wood MA (2011) HDAC3 is a critical negative regulator of long-term memory formation. J Neurosci 31:764-774.

Miller CA, Sweatt JD (2007) Covalent modification of DNA regulates memory formation. Neuron 53:857-869.

Miller CA, Campbell SL, Sweatt JD (2008) DNA methylation and histone acetylation work in concert to regulate memory formation and synaptic plasticity. Neurobiol Learn Mem 89:599-603.

Narlikar GJ, Fan HY, Kingston RE (2002) Cooperation between complexes that regulate chromatin structure and transcription. Cell 108:475-487.

Oliveira AM, Wood MA, McDonough CB, Abel T (2007) Transgenic mice expressing an inhibitory truncated form of p300 exhibit long-term memory deficits. Learn Mem 14:564-572.

Padhye S, Ahmad A, Oswal N, Sarkar FH (2009) Emerging role of Garcinol, the antioxidant chalcone from Garcinia indica Choisy and its synthetic analogs. J Hematol Oncol 2:38.

Ricobaraza A, Cuadrado-Tejedor M, Pérez-Mediavilla A, Frechilla D, Del Río J, García-Osta A (2009) Phenylbutyrate ameliorates cognitive deficit and reduces tau pathology in an Alzheimer's disease mouse model. Neuropsychopharmacology 34:1721-1732.

Selvi BR, Cassel JC, Kundu TK, Boutillier AL (2010) Tuning acetylation levels with HAT activators: therapeutic strategy in neurodegenerative diseases. Biochim Biophys Acta 1799:840-853.

Stefanko DP, Barrett RM, Ly AR, Reolon GK, Wood MA (2009) Modulation of long-term memory for object recognition via HDAC inhibition. Proc Natl Acad Sci U S A 106:9447-9452.

Strahl BD, Allis CD (2000) The language of covalent histone modifications. Nature 403:41-45.

Vecsey CG, Hawk JD, Lattal KM, Stein JM, Fabian SA, Attner MA, Cabrera SM, McDonough CB, Brindle PK, Abel T, Wood MA (2007) Histone deacetylase inhibitors enhance memory and synaptic plasticity via CREB: CBP-dependent transcriptional activity. J Neurosci 27:6128-6140.

Weng MS, Liao CH, Yu SY, Lin JK (2011) Garcinol promotes neurogenesis in rat cortical progenitor cells through the duration of extracellular signalregulated kinase signaling. J Agric Food Chem 59:1031-1040.

Wood MA, Kaplan MP, Park A, Blanchard EJ, Oliveira AM, Lombardi TL, Abel T (2005) Transgenic mice expressing a truncated form of CREBbinding protein (CBP) exhibit deficits in hippocampal synaptic plasticity and memory storage. Learn Mem 12:111-119.

Wood MA, Attner MA, Oliveira AM, Brindle PK, Abel T (2006) A transcription factor-binding domain of the coactivator CBP is essential for long-term memory and the expression of specific target genes. Learn Mem 13:609-617.

Yang XJ, Seto E (2007) HATs and HDACs: from structure, function and regulation to novel strategies for therapy and prevention. Oncogene 26:5310-5318.

Zhao Z, Fan L, Frick KM (2010) Epigenetic alterations regulate the estradiol-induced enhancement of memory consolidation. Proc Natl Acad Sci U S A 107:5605-5610. 